\title{
Knowledge, Attitude and Practice of Human Papilloma Virus Vaccine Amongst Medical Student in Central India
}

\author{
Riya Joshi', Swarupa Chakole ${ }^{2}$ and Neha Bhatt ${ }^{3}$ \\ ${ }^{1}$ First Year MBBS first year Student Datta Meghe Medical College, \\ Shalinitai Meghe Hospital and Research Centre, Nagpur, India \\ ${ }^{2}$ Department of Community Medicine Jawaharlal Nehru Medical College, \\ Datta Meghe Institute of Medical Sciences Sawangi (Meghe) Wardha \\ ${ }^{3}$ Department of Pathology Datta Meghe Medical College, Shalinitai Meghe \\ Hospital and Research Centre, Nagpur,India \\ Corresponding author email: nehabhatt1381@gmail.com
}

\section{ABSTRACT}

To assess the knowledge of cervical cancer prevention amongst medical student in central India studying in a medical college. Cross sectional, observationalstudy. A structured questionnaire was sent to all female medical students studying in the first year of the allopathic medicine. Details about demographic profile and knowledge of cervical cancer and its prevention were collected. Willingness to receive the human papilloma vaccine was assessed. The data were entered in an excel sheet and subjected to statistical analysis. Out of 90 students 67 responded (74.4\%).The mean age of participants was $21.5 \pm 5.5$ years.93.8\% people were aware of cervical cancer. $80 \%$ of the respondent replied that they are aware about HPV Vaccine.32.4\% respondents came to know about HPV vaccine through school/ college.50\% respondents are not aware about the doses of HPV vaccine .73.5\% respondents have taken the HPV vaccine.97.1\% didn't experience any side effects after taking the vaccines $.80 .9 \%$ respondents think that HPV vaccine should be a part of National Immunisation Programme. The study suggests that overall knowledge about cervical cancer and its prevention by HPV vaccine is good amongst medical. 73.5\% students have taken HPV vaccine which suggests awareness about vaccine. Inclusion of knowledge about the disease and its prevention in the curriculum will help in the prevention of the cervical cancer. Social media, television, radio and newspaper are other media to create awareness. We recommend inclusion of the vaccination in the National Programme for immunisation.

KEY WORDS: HUMAN PAPILLOMA VIRUS, CERVICAL CANCER, KERATOREFRACTIVE SURGERY, VACCINE FOR PREVENTION OF CERVICAL CANCER.

\section{INTRODUCTION}

(Duenas-Gonzalez et al.2014) World over cervical cancer is the fourth most leading cause of cancer death. (Dikshit et al. 2012 and Pratapa et al. 2020) In India it is the leading cause of cancer in women accounting to

Biosc Biotech Res Comm P-ISSN: 0974-6455 E-ISSN: 2321-4007

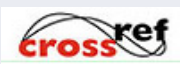

Identifiers and Pagination

Year: 2021 Vol: 14 No (6) Special Issue

Pages: 29-32

This is an open access article under Creative

Commons License Attribn 4.0 Intl (CC-BY).

DOI: $h t t p: / / d x$.doi.org/10.21786/bbrc/14.6.6
74,000 deaths per year. Human papilloma virus (HPV) related disease is the most common cause of cervical cancer. HPV is the most common viral infection of the reproductive system. Various modes of infection have been noted. These include skin-to-skin and sexually transmitted contact. The infection is acquired in both males and females after becoming sexually active.More than 140 types of HPV have been detected only 40 types are sexually transmitted. (Das et al.1992, Pillai et al.2010 and Warke et al.2011) amongst them two high risk V types 16 and 18 are responsible for more than $80 \%$ of cervical cancer in India.

Most of the HPV infections and precancerous infections clear spontaneously without any residual. However,

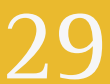


there are certain predispositions for the persistence of the infection and the development of the precancerous lesions. These include HPV virus infection with its oncogenic strength, immune status of the individual with immune compromised host having persistent HPV infection, co-infection with other sexually transmitted agents like chlamydia, gonorrhoea, syphilis and herpes simplex, young age at birth, tobacco chewers and smokers.

Prevention is always better than cure. Strategies followed in the prevention of cervical cancer include vaccination, creating awareness and knowledge about cervical cancer and modification of lifestyle. Vaccination against HPV is available in India for the vaccination of young adolescent and young adults. However, vaccination against HPV is not the part of National programme for immunisation in India. The present study is done with aim to assess the knowledge of cervical cancer and its prevention by HPV vaccine amongst medical student studying in the first year of allopathic system of education in central India.

\section{MATERIAL AND METHODS}

The study was conducted in the month of april 2021 amongst medical students and non medical students. The students were from educated and affluent family with access to internet. All students were from urban area. Informed consent was obtained from all the

Questioners employed for the study:

\begin{tabular}{|c|c|c|}
\hline \multicolumn{3}{|c|}{ Table 1} \\
\hline S.no & Questions & Response \\
\hline 1] & $\begin{array}{c}\text { Do you know } \\
\text { about HPV } \\
\text { Vaccine? }\end{array}$ & Yes/ No \\
\hline 2] & $\begin{array}{l}\text { Are you aware of } \\
\text { cervical cancer? }\end{array}$ & Yes / No \\
\hline 3] & $\begin{array}{l}\text { From where did you } \\
\text { hear about HPV vaccine? }\end{array}$ & $\begin{array}{c}\text { School / college } \\
\text { Friends } \\
\text { Doctors } \\
\text { Internet } \\
\text { Others } \\
\text { Newpapers }\end{array}$ \\
\hline 4] & $\begin{array}{c}\text { How many doses of } \\
\text { HPV vaccine } \\
\text { are recommended } \\
?\end{array}$ & $\begin{array}{c}\text { Not aware } \\
1 \\
2 \\
3\end{array}$ \\
\hline 5] & $\begin{array}{l}\text { What is the age } \\
\text { limit for } \\
\text { vaccination } \\
\text { [HPV] }\end{array}$ & \\
\hline 6] & Have you taken HPV vaccine? & Yes / No \\
\hline 7] & At what age did you take HPV vaccine? & \\
\hline 8] & If not what were the reasons? & $\begin{array}{c}\text { Costly } \\
\text { Not aware } \\
\text { Not required } \\
\text { Afraid of side effects }\end{array}$ \\
\hline 9] & If yes did you experience any side effects? & Yes / No \\
\hline 10] & If taken the vaccine will you recommend it to others? & Yes /No/Maybe \\
\hline 11] & $\begin{array}{l}\text { Do you think it should be a } \\
\text { part of National Immunisation Programme? }\end{array}$ & Yes /No/Maybe \\
\hline
\end{tabular}

Statistical Analysis: All the data was entered in an excel sheet and statistical analysis was performed. Continuous variables were described in the form of mean and standard deviation and categorical variables by percentages.

\section{RESULTS}

The questionnaire was sent to 90 students. Out of 90 students 67 responded (the response rate was 74.4\%).The questionnaire was sent to all the female participants. The mean age of participants was $21.5 \pm 5.5$ years minimum 17 years andmaximum 23years. 
Despite advances in the prevention of cancer, cervical cancer is the leading cause of death in women in India. An attempt have been made to identify the awareness about cervical cancer and its prevention by Human papilloma virus (HPV) vaccine in medical students, who are going to be future doctors and likely to treat or advice about the prevention of the cervical cancer in some part of life. The response rate for the questionnaire sent was 74.4\%. We could not analyse the reasons for the unresponsiveness in rest of the participants as it was beyond the scope of the study. As the present study was conducted amongst female only the knowledge about the cervical cancer was seen in 93.8\% respondents and about $80 \%$ students were aware of HPV vaccine. (Selvam et al. 2020) This correlates with study done by Rashid et al. who have shown that girls who have passed from biology background are aware of cervical cancer. (Dhadse et al. 2020) Blodt have also shown the knowledge of vaccination is more in females than the male.

Figure 1: 93.8\% people were aware of cervical cancer.

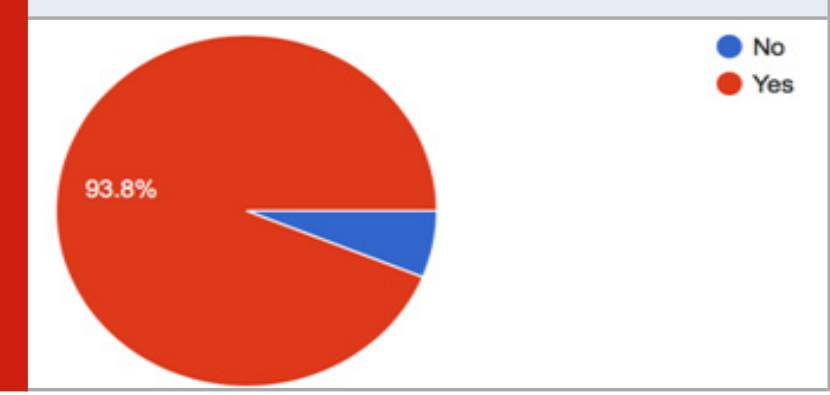

Figure 2: $80 \%$ of the respondent replied that they are aware about HPV Vaccine.

Do you know about HPV Vaccine?

65 responses

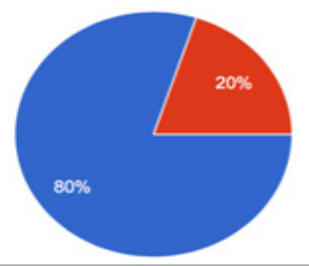

Figure 3: 32.4\% respondents came to know about HPV vaccine through school/ college.

From where did you hear about HPV vaccine?

68 responses
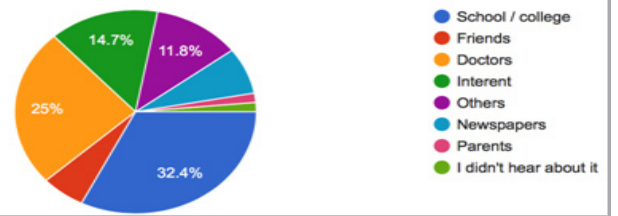

$14.7 \%$ students had never heard about vaccination. Maximum respondents (32.4\%) had knowledge of vaccination through school suggesting that preventive measures about the disease should be incorporated in the curriculum. Same thing applies to other diseases also. That is the way by which we can prevent many diseases. There is need to include the knowledge about vaccination from prepubertal age. 50\% respondents were not aware of the doses of HPV vaccine. We put this question across all the participants to know whether they are aware of the doses of the vaccine or not. Completion of the doses of vaccine is important to have immunity against the HPV. By knowing so the present survey will try to educate the participants.

Figure 4: 50\% respondents are not aware about the doses of HPV vaccine

How many doses of HPV vaccine are recommended?

68 responses

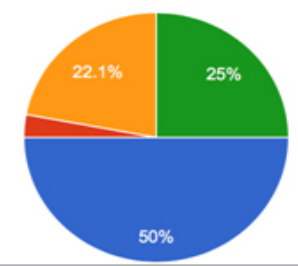

Figure 5: 73.5\% respondents have taken the HPV vaccine.

Have you taken HPV vaccine?

68 responses

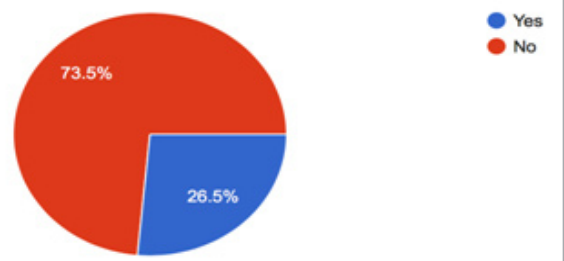

Figure 6: 97.1\% didn't experience any side effects after taking the vaccines.

If Yes did you experience any side effects? 68 responses

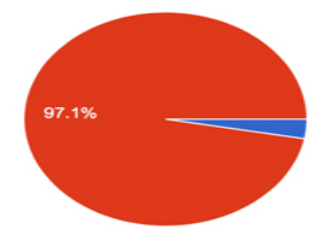

Figure 7: 757.4\% respondents said that they will recommend the vaccine to others.

If taken the vaccine will you recommend it to others

68 responses

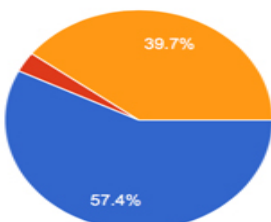


Figure 8: 80.9\% respondents think that HPV vaccine should be a part of National Immunisation Programme. Do you think it should be a part of National Immunisation Programme? 68 responses
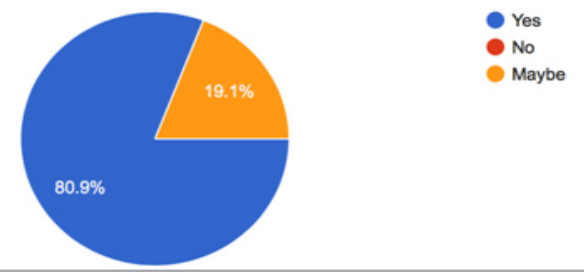

In the present survey $73.5 \%$ participants have received vaccination. Willingness to vaccinate has been studied in various studies. (Saha et al.2010, Balwani et al.2018, Pandey et al.2012 and Mehta et al. 2013) Amongst medical (60-88\%) and non- medical students (64-75\%) there have been good response to vaccinate. We also studied whether side effects of the vaccine were experienced by the participants or not. 97.1\% reported that they did not experience side effects. That will carry positive response in the community. Acceptance for the vaccine will improve by mouth to mouth spread of the good words. Therefore, 57.4\% participants have said that they will recommend vaccine to their near and dear. 80.9\% respondents responded saying that HPV vaccination should be included in the National Immunisation programme. Inclusion in the National programme will benefit underprivileged strata of the society as the HPV vaccination is administered in private clinics and hospitals only.

\section{CONCLUSION}

The study suggests that overall knowledge about cervical cancer and its prevention by HPV vaccine is good amongst medical students studying in the first year of the medical college. It is good that 73.5\% students have taken HPV vaccine. But still awareness is required to be done particularly in the prepubertal age. Inclusion of knowledge about the disease and its prevention in the curriculum will help in the prevention of the cervical cancer. Social media, television, radio and newspaper are other media to create awareness. We recommend inclusion of the vaccination in the National Programme for immunisation.

\section{REFERENCES}

Balwani, M., Bawankule, C., Ramteke, V. and Pasari, A., 2018. Hepatitis C virus, directly acting antivirals and Guillain-Barré syndrome. Saudi Journal of Kidney Diseases and Transplantation, 29(5), p.1237.

Das, B.C., Gopalkrishna, V., Sharma, J.K., Roy, M. and Luthra, U.K., 1992. Human papillomavirus DNA in urine of women with preneoplastic and neoplastic cervical lesions. The Lancet, 340(8832), pp.1417-1418.
Dhadse, P.V., Sethiya, K.R., Subhadarsanee, C. and Durge, K., 2020. The novel corona virus (nCoV2) seems to defy all laws of virology.

Dikshit, R., Gupta, P.C., Ramasundarahettige, C., Gajalakshmi, V., Aleksandrowicz, L., Badwe, R., Kumar, R., Roy, S., Suraweera, W., Bray, F. and Mallath, M., 2012. Cancer mortality in India: a nationally representative survey. The Lancet, 379(9828), pp.1807-1816.

Duenas-Gonzalez, A., Serrano-Olvera, A., Cetina, L. and Coronel, J., 2014. New molecular targets against cervical cancer. International journal of women's health, 6, p.1023.

Latchoumi, T.P., Ezhilarasi, T.P. and Balamurugan, K., 2019. Bio-inspired weighed quantum particle swarm optimization and smooth support vector machine ensembles for identification of abnormalities in medical data. SN Applied Sciences, 1(10), pp.1-10.

Mehta, S., Rajaram, S., Goel, G. and Goel, N., 2013. Awareness about human papilloma virus and its vaccine among medical students. Indian journal of community medicine: official publication of Indian Association of Preventive \& Social Medicine, 38(2), p.92.

Pandey, D., Vanya, V., Bhagat, S., Binu, V.S. and Shetty, J., 2012. Awareness and attitude towards human papillomavirus (HPV) vaccine among medical students in a premier medical school in India. PloS one, 7(7), p.e40619.

Pillai, R.M., Babu, J.M., Jissa, V.T., Lakshmi, S., Chiplunkar, S.V., Patkar, M., Tongaonkar, H., Reddy, K.B., Chakka, K.N., Siddiqui, M. and Roychoudury, S., 2010. Region-wise distribution of high-risk human papillomavirus types in squamous cell carcinomas of the cervix in India. International Journal of Gynecologic Cancer, 20(6).

Pratapa, S.K., Acharya, S., Gupte, Y. and Shukla, S., 2020. Acute B Virus Hepatitis with Fulminant Hepatic Failure Precipitating Crisis in Sickle Cell Disease.

Saha, A., Chaudhury, A.N., Bhowmik, P. and Chatterjee, R., 2010. Awareness of cervical cancer among female students of premier colleges in Kolkata, India. Asian Pac J Cancer Prev, 11(4), pp.1085-90.

Selvam, S., Taksande, A., Lohakare, A. and Meshram, R., 2020. An Infant with Congenital Cytomegalovirus Infection Presenting with Hypomelanosis of Ito. Journal of Evolution of Medical and Dental Sciences, 9(48), pp.3697-3700.

Warke, H. and Chaudhari, H., 2020. 4. Kerkar SC, Latta S, Salvi V, Mania-Pramanik J. Human papillomavirus infection in asymptomatic population. Sex Reprod Healthc 2011; 2: 7-11. 5. Ray K, Bala M, Bhattacharya M, Muralidhar S, Kumari M, Salhan S. Prevalence of RTI/STI agents and HIV infection in symptomatic and. Indian Journal of Dermatology, Venereology and Leprology, 86(5), p.586. 